\title{
Recurrent Hemorrhoids-Efficacy, Utility and Initial Experience with the Use of Stapled Hemorrhoidopexy in Recurrent Hemorrhoids
}

\author{
Ajaz Ahmed Wani ${ }^{1}$ Suhail Khuroo ${ }^{1}$ Vikas Kumar Heer ${ }^{2}$ Saurabh Kumar Jain ${ }^{3 \odot}$

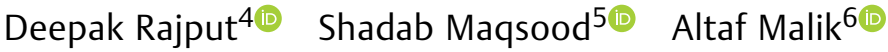

${ }^{1}$ Department of Surgical Gastroenterology, Shri Mata Vaishno Devi Narayana Super Specialty Hospital, Kakryal, Katra, Jammu And Kashmir, India

2 Department of Surgical Oncology, Shri Mata Vaishno Devi Narayana Super Specialty Hospital, Kakryal, Katra, Jammu And Kashmir, India

Address for correspondence Ajaz Ahmed Wani, MBBS, DNB, FMAS, MNAMS, Shri Mata Vaishno Devi Narayana Superspeciality Hospital,

${ }^{3}$ Department of Surgical Gastroenterology, Action Cancer Hospital, Jammu, Jammu \& Kashmir, India (e-mail: drajazwani11@gmail.com).

New Delhi, India

${ }^{4}$ Department of General Surgery, All India Institute of Medical

Sciences, Rishikesh, Uttarakhand, India

${ }^{5}$ Department of Radiology, Sher I Kashmir Institute of Medical

Sciences, Srinagar, Jammu And Kashmir, India

${ }^{6}$ Department of General Surgery, Government Medical College,

Doda, Jammu And Kashmir, India

J Coloproctol 2021;41(3):281-285.

\begin{abstract}
Keywords

- stapled hemorrhoidectomy

- conventional hemorrhoidectomy

- circular anal dilator repeat stapled hemorrhoidectomy

Overview Hemorrhoidal disease (HD) is a common surgical disorder. The treatment modalities can be surgical or nonsurgical. Every surgical option has its own indications and limitations. Postsurgical symptomatic recurrence rates are low and vary between different techniques. The ideal way to deal with recurrent $\mathrm{HD}$ is not clear.

Material and Methods The present prospective case series enrolled a total of 87 patients ( 54 male/33 female). Thirteen out of 87 patients (15\%) had history of previous intervention for HD. A modification of the standard technique was adopted for patients with recurrent HD. A mean follow-up of 22 months was achieved.

Results Stapled hemorrhoidectomy (SD) was performed in 13 patients who had history of previous surgical intervention for HD. There were no adverse events related to the technique. Patients with recurrent $\mathrm{HD}$ had severe pain scores with $\mathrm{SH}$ as compared to patients who underwent $\mathrm{SH}$ at the first time. There were no wound related complications. Conclusion Stapled hemorrhoidectomy can be performed easily and offers good results in patients with recurrent HD.
\end{abstract}

\section{Introduction}

Hemorrhoidal disease (HD) is one of the most common anorectal disorders and ranks amongst the most frequent rea- sons of visit to any outpatient surgical facility. The prevalence reported in literature varies. Approximately 4.4 to $36.4 \%$ of the general population may be affected by HD. ${ }^{1}$ received

September 14, 2020

accepted

January 18, 2021

published online

June 3, 2021
DOI https://doi.org/

10.1055/s-0041-1730262.

ISSN 2237-9363.

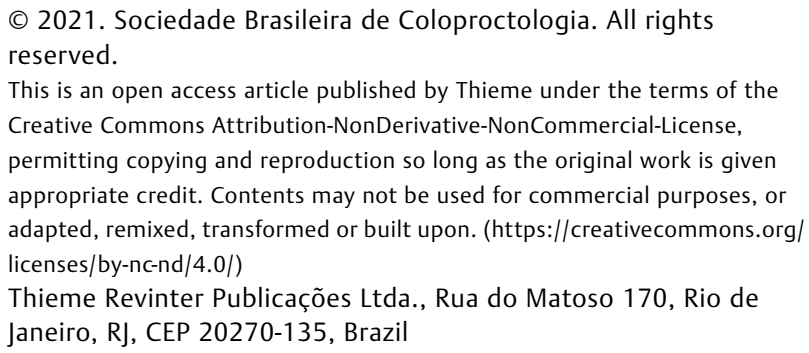

(c) 2021. Sociedade Brasileira de Coloproctologia. All rights reserved.

This is an open access article published by Thieme under the terms of the Creative Commons Attribution-NonDerivative-NonCommercial-License, permitting copying and reproduction so long as the original work is given appropriate credit. Contents may not be used for commercial purposes, or adapted, remixed, transformed or built upon. (https://creativecommons.org/ licenses/by-nc-nd/4.0/)

Thieme Revinter Publicações Ltda., Rua do Matoso 170, Rio de Janeiro, RJ, CEP 20270-135, Brazil 
These figures may be an underestimation of the actual disease burden, as a substantial percentage of patients suffering from HD may not report it to a physician; besides, many patients suffering from HD have minimal symptoms and may not seek medical help.

Hemorrhoids are classified as internal or external, depending upon their location proximal or distal to the dentate line, respectively. ${ }^{2}$ Internal hemorrhoids (IH) are derived from the endoderm. They are covered by columnar epithelium, innervated by visceral nerve fibers and are not painful. Internal hemorrhoids are further classified depending upon the severity of the prolapse. ${ }^{3}$ External hemorrhoids (EH) are disease components which are present distal to the anoderm. They develop from the ectoderm and are covered with anoderm, which is composed of squamous epithelium. They are innervated by somatic nerves supplying the perianal skin and are extremely painful. External hemorrhoids and their sequelae in the form of skin tags interfere with perianal hygiene and may result in pruritus and skin excoriation. External hemorrhoids may undergo thrombosis, which is a very painful condition. Unlike IH, EH are not graded. Internal and external components may coexist together and are termed as interno-external hemorrhoids.

Hemorrhoidal disease patients present with complaints of bleeding per rectum, varying degree of prolapse, and pruritis ani. ${ }^{3}$ The bleeding is bright red, painless and occurs towards the end of defecation. The presence of pain usually indicates affliction of $\mathrm{EH}$ and/or coexistence of an alternate pathology, like fissure, fistula, or an abscess. ${ }^{4}$ Both genders report a peak incidence between the ages of 45 and 65 years.

Hemorrhoidectomy provides an effective and durable response when compared to rubber band ligation and sclerotherapy. ${ }^{5}$ Surgical intervention for HD is associated with more pain and more complications than conservative or endoscopic treatment. ${ }^{6}$ Stapled hemorrhoidopexy (SH) offers benefits, such as shorter operative time, decreased postoperative pain, and earlier recovery. ${ }^{7}$ Comparisons between the long-term results of conventional treatment and $\mathrm{SH}$ in terms of recurrence and symptom relief have been controversial.

The treatment guidelines and therapeutic options for patients with recurrent HD (patients with history of previous endoscopic or surgical intervention) are not well defined. The aim of the present study was to evaluate the utility and effectiveness of $\mathrm{SH}$ in the treatment of recurrent $\mathrm{HD}$.

\section{Material and Methods}

\section{Study Population}

The study population comprised of 87 consecutive patients who underwent $\mathrm{SH}$ at our institute. Fifty-four out of 87 patients (62\%) were male. Thirteen out of 87 (15\%) patients had previous history of surgical intervention for HD. Among the recurrent HD patients, 10 had undergone conventional hemorrhoidectomy $(\mathrm{CH})$, and 3 had undergone $\mathrm{SH}$. For the current study, recurrent HD was defined as those patients who had previously underwent a surgical procedure for HD. Patients who had undergone previous rubber band ligation
(RBL) or sclerotherapy were not enrolled in this study. Diagnosis of recurrent HD was confirmed by visualization of hemorrhoidal masses by outpatient anoscopy.

\section{Surgical Technique}

The surgical technique used in patients who were operated for the first time was the same as the one described and validated by the consensus position paper by Corman et al. ${ }^{8}$ For patients with recurrent HD, a modification of the abovementioned technique was adopted, as described by Raahave et al. ${ }^{9}$ This new technique differed from the original description as follows. After introduction of the stapler through the circular anal dilator (CAD) and retrieval of the suture ends by the suture passer, the anchoring sutures of the CAD are released. This release enables the prolapsed loose ano-rectal mucosa distal to the purse-string suture/future staple line to migrate proximally into the ano-rectum when the stapler is closed. The result is complete and wider doughnuts, thus ensuring a better-pexy (fixation) along with circumferential reduction of prolapse.

\section{Postoperative Care and Follow Up}

All patients received analgesics and stool softeners at discharge. The first follow-up was on the $10^{\text {th }}$ postoperative day, and the second follow-up was at 2 months. The mean followup was 22 months. Response to surgery in terms of relief of symptoms, such as bleeding, prolapse, wound complications, and return to work, was noted.

\section{Results}

A total of 87 (54 males) patients were enrolled. The mean age of the patients was 53.4 years. Thirteen out of 87 (15\%) patients had history of previous intervention for HD. Sixtytwo out of 87 patients (72\%) received a spinal block, 22 out of 87 patients (26\%) received general anesthesia, and 3 out of 87 patients (2\%) underwent the procedure in a caudal anal block. All patients were clinically continent.

Patients with recurrent HD had worse pain scores (visual analog scale [VAS]) on postoperative days 1 and 10 , with significantly higher analgesic requirements during the $1^{\text {st }}$ postoperative week. Stapled hemorrhoidectomy offered a substantial reduction in the degree of prolapse in both first-time operated patients as well as in those patients operated for recurrent HD.

Stapled hemorrhoidectomy provided significant benefit in terms of wound-related complications. As the staple line lies within the pain insensitive endoderm, there is minimal pain. An open wound after a $\mathrm{CH}$ acts as a source of pain, discharge, and discomfort. It requires constant attention and cleaning, frequently soils garments, and significantly delays return to work.

The numbers in our study were not enough for a statistical conclusion to be drawn. However, the short- and intermediate-term results have shown promising trends in favor of $\mathrm{SH}$ being utilized in the treatment of recurrent HD. A large-scale randomized trial enrolling a large number of patients will address the shortcomings in our understanding on the surgical intervention in recurrent HD. 


\section{Discussion}

Hemorrhoidal disease is a common referral to any surgical clinic. Anatomically, hemorrhoids have been divided into internal and external components. Internal hemorrhoids are further subclassified depending upon the severity of their prolapse (Goligher classification) $)^{10}$ - Grade I IH: Bleeding with no prolapse; Grade II IH: Bleeding + prolapse on straining but with spontaneous reduction; Grade III IH: Bleeding + prolapse on straining or exertion with manual reduction required; and Grade IV IH: irreducible prolapse. The single pile hemorrhoid classification (SPHC) system enrolls the number of pathological piles, the characteristics of each internal pile as per the Goligher classification, and the characteristics of each external pile. ${ }^{11}$ The Sodergren score uses pain at rest, frequency of pruritus, painful defecation, and prolapse as the criteria to determine the severity of HD. ${ }^{12}$ In the PATE 2000-Sorrento study, position (internal vs external) and acute conditions (edema, thrombosis) as well as anal sphincter tone (low, medium, high) were used. The revised version (PATE 2006) included symptoms along with the previously mentioned criteria. ${ }^{13}$ A colonoscopy-based classification system including circumferential degree, size, and red color signs (similar to the esophageal variceal grading) has also been described. ${ }^{14}$ These new classification systems are complex to use and have failed to gain widespread popularity.

Excisional hemorrhoidectomy, along with its variants, is considered the gold standard for the treatment of hemorrhoids. The open - (Milligan-Morgan) and closed (Ferguson) hemorrhoidectomies are the most commonly used techniques. The semi-closed techniques of Sokol/Borba and RuizMereno, the sub-mucosal technique of Parks, and the Whiteheads amputative technique are amongst the many modifications to those classic open procedures. Excision of the hemorrhoidal tissue can be completed with a variety of instruments, like scissors, diathermy, LigaSure (Covidien, Medtronic, Ireland, Dublin), and harmonic scalpel. Diathermy use is associated with a shorter operating time and less bleeding, but without much difference in the postoperative pain scores. ${ }^{15}$ When compared with conventional procedures, LigaSure hemorrhoidectomy has shown clear benefits in terms of operative time, lower scores of postoperative pain, less incidence of urinary retention along with possible earlier return to work. ${ }^{16}$ The results of harmonic scalpel have shown mixed response of its benefits and drawbacks. ${ }^{17,18}$

Excisional hemorrhoidectomy is the gold standard treatment modality for hemorrhoids. It has the lowest recurrence rate $^{6}$ and has stood the test of time. The procedure can also be tailored individually as per patient needs. Postoperative complications include acute urinary retention (2-36\%), reactionary and secondary hemorrhage (0.03-6\%), infective complications (0.5-5.5\%), wound related issues, decreased anal sensation, anal stricture (0-6\%), and even fecal incontinence $(2-12 \%) .^{19-21}$

To address the pain and wound-related complications associated with conventional open procedures, Longo, in 1998, described the use of a specially designed circular stapler (Ethicon endosurgery) for the treatment of high grades of hemorrhoids. ${ }^{22}$ Stapled hemorrhoidopexy (also called procedure for prolapse and hemorrhoids [PPH]) aims at circumferential reduction of the prolapse by excision of a complete ring of rectal mucosa above the dentate line. Along with reduction of the prolapse, it also anchors the prolapsed distal hemorrhoids to the lower rectal muscular wall. The circular stapler mechanism also transects branches of superior hemorrhoidal arteries, which, in turn, leads to decreased venous congestion and subsequent reduction in size of the hemorrhoidal plexus (akin to esophago-gastric devascularization procedures). Absence of a wound coupled with location of the stapler line in the pain insensitive distal rectal mucosa leads to a considerable reduction in pain scores.

Stapled hemorrhoidectomy offers several short-term benefits, such as shorter operative time, less postoperative pain and urinary retention, and an earlier return to physical activity. The long-term outcomes of $\mathrm{SH}$ when compared with $\mathrm{CH}$ have been debated upon, especially regarding residual skin tags and recurrent/persistent prolapse. ${ }^{23,24}$ It is difficult to ascertain whether the prolapse is a remnant of the initial severe prolapse or de novo recurrence of prolapse. The conventional open techniques also allow for a tailored approach to address skin tags and $\mathrm{EH}$, unlike the ready-made "one size fits all" approach provided by $\mathrm{SH}$.

Guenin et al., ${ }^{25}$ in their long term follow-up, reported a secondary intervention rate of $0.8 \%$ after conventional Ferguson hemorrhoidectomy. Ceci et al., ${ }^{26}$ in their 5 year follow-up of patients post $\mathrm{SH}$, noted a recurrence rate of $18.2 \%$ and a reoperation rate of $7.2 \%$. A symptom-based comparison between $\mathrm{CH}$ and $\mathrm{SH}$ fails to reveal superiority of either modality, except for the higher incidence of asymptomatic prolapse in the $\mathrm{SH}$ group. This may partly explain the apparent lack of difference between these groups in the long term, as the symptoms related to such recurrences are minimal. ${ }^{26} \mathrm{~A}$ distinction between the presenting symptoms after recurrence seems important. When recurrent or persistent bleeding is the symptom, it can be adequately managed by RBL (rubber band ligation) or THD (trans anal hemorrhoidal de-arterialization). For patients who present with recurrent/persistent prolapse, the conventional approach has been a need-based tailored open procedure. ${ }^{27}$ We performed a repeat SH for 13 patients after recurrence of symptoms. Prolapse and pruritus were the main presenting complaints in our patients. Ten patients had undergone open hemorrhoidectomy as the initial procedure, while 3 patients had undergone $\mathrm{SH}$ as the initial procedure.

Raahave et al. ${ }^{9}$ reported their experience of repeat $\mathrm{SH}$ with 31 patients who had recurrent prolapse. They reported higher pain scores in patients who underwent repeat SH than in the first SH. Our study also revealed similar results, with the pain scores being higher in patients with repeat $\mathrm{SH}$ than control patients. Festen et al. ${ }^{27}$ reported a symptomatic recurrence rate of $16 \%$, and a secondary intervention rate (repeat $\mathrm{SH}$ ) of $8 \%$. The repeat $\mathrm{SH}$ patients in their study had similar analgesic requirement as compared to controls.

The position of the final staple line has been postulated to correlate with the pain scores. In the study by Raahave et al., ${ }^{9}$ 
the mean position of the staple line at the second SH was $1.5 \mathrm{~cm}$ proximal to the dentate line, significantly lower than the mean position at the first $\mathrm{SH}$, which was around $2.25 \mathrm{~cm}$. Festen at al. ${ }^{27}$ reported that in most of the patients who received a second $\mathrm{SH}$, the new stapler line was situated below the first one. They suggested that high location of the staple line in the initial procedure may be a reason for inadequate prolapse reduction, thus contributing towards recurrence of prolapse. They reported a change in technique over the years by using the apex of the hemorrhoidal plexus rather than using the dentate line as the reference for purse string suture to attain good prolapse reduction.

High recurrence rate after $\mathrm{SH}$ in grade IV hemorrhoids (severe initial prolapse) may result because of incomplete mucosal resection, which may occur when width/degree of prolapse far exceeds the width of the excised doughnut/volume of the stapler fire. This may explain why $4^{\text {th }}$ degree hemorrhoids do not form an ideal indication for $\mathrm{SH}$. The recurrence rate in $3^{\text {rd }}$ degree hemorrhoids seems comparable between $\mathrm{SH}$ and $\mathrm{CH}^{28}$

To decrease the rate of recurrence after $\mathrm{SH}$, a modified technique of double stapled hemorrhoidopexy (DSH) has been described for severe degrees of initial prolapse. Double stapled hemorrhoidopexy in cases with severe initial prolapse (occupying half or more of the CAD) addresses the volumetric inadequacy of a single SH and can achieve a higher degree of prolapse reduction and better resolution of symptoms. ${ }^{29}$ Stuto et al. reviewed the utility of DSH and recommended that double stapler PPH03 technique is safe and effective with lower incidence of relapse in the long term. ${ }^{30}$

Complications, length of stay, recurrence and re-intervention rates are quality parameters utilized for the evaluation of any surgical intervention. However, from the patient's perspective, criteria such as quality of life, satisfaction with the procedure, and chances of a secondary procedure influence decision making when choosing one surgical procedure over the other. These criteria may favor patient's selection of $\mathrm{SH}$ over $\mathrm{CH}^{31}$

\section{Conclusion}

Postoperative pain is a major concern in excisional procedures. Stapled hemorrhoidopexy reduces postoperative pain, and hospitalization and operation times. Repeated SH can be performed safely and with satisfactory results in patients with recurrent hemorrhoids. The utility of a repeat $\mathrm{SH}$ in the setting of recurrence needs to be fully explored.

\section{Conflict of Interests}

The authors have no conflict of interests to declare.

\section{References:}

1 Loder PB, Kamm MA, Nicholls RJ, Phillips RK. Haemorrhoids: pathology, pathophysiology and aetiology. Br J Surg 1994;81 (07):946-954

2 Thomson WH. The nature of haemorrhoids. Br J Surg 1975;62 (07):542-552
3 Sardinha TC, Corman ML. Hemorrhoids. Surg Clin North Am 2002; 82(06):1153-1167, vi

4 Johanson JF. Evidence based approach to the treatment of hemorrhoidal disease. Evidence Based Gastroenterology 2002;3:26-31

5 Rivadeneira DE, Steele SR, Ternent C, et al. Standards practice task force of the American society of colon and rectal surgeons. Practice parameters for the management of hemorrhoids. Dis Colon Rectum 2010;54:1059-1064

6 MacRae HM, McLeod RS. Comparison of hemorrhoidal treatment modalities. A meta-analysis. Dis Colon Rectum 1995;38(07):687-694

7 Shao WJ, Li GC, Zhang ZH, Yang BL, Sun GD, Chen YQ. Systematic review and meta-analysis of randomized controlled trials comparing stapled haemorrhoidopexy with conventional haemorrhoidectomy. Br J Surg 2008;95(02):147-160

8 Corman ML, Gravié JF, Hager T, et al. Stapled haemorrhoidopexy: a consensus position paper by an international working party indications, contra-indications and technique. Colorectal Dis 2003;5(04):304-310

9 Raahave D, Jepsen LV, Pedersen IK. Primary and repeated stapled hemorrhoidopexy for prolapsing hemorrhoids: follow-up to five years. Dis Colon Rectum 2008;51(03):334-341

10 Goligher JC. Surgery of the anus, rectum and colon. 5th ed. London: Billiere Tindall; 1984:101

11 Elbetti C, Giani I, Novelli E, Fucini C, Martellucci J. The single pile classification: a new tool for the classification of haemorrhoidal disease and the comparison of treatment results. Updates Surg 2015;67(04):421-426

12 Pucher PH, Qurashi M, Howell AM, et al. Development and validation of a symptom-based severity score for haemorrhoidal disease: the Sodergren score. Colorectal Dis 2015;17(07):612-618

13 Gaj F, Trecca A, Busotti A, Brugiotti C, Carboni M. The new classification of hemorrhoids: PATE 2000-Sorrento. History of the scientific debate. Minerva Chir 2002;57(03):331-339

14 Fukuda A, Kajiyama T, Kishimoto H, et al. Colonoscopic classification of internal hemorrhoids: usefulness in endoscopic band ligation. J Gastroenterol Hepatol 2005;20(01):46-50

15 Armstrong DN, Frankum C, Schertzer ME, Ambroze WL, Orangio GR. Harmonic scalpel hemorrhoidectomy: five hundred consecutive cases. Dis Colon Rectum 2002;45(03):354-359

16 Chung YC, Wu HJ. Clinical experience of sutureless closed hemorrhoidectomy with LigaSure. Dis Colon Rectum 2003;46(01): 87-92

17 Khan S, Pawlak SE, Eggenberger JC, et al. Surgical treatment of hemorrhoids: prospective, randomized trial comparing closed excisional hemorrhoidectomy and the Harmonic Scalpel technique of excisional hemorrhoidectomy. Dis Colon Rectum 2001; 44(06):845-849

18 Chung CC, Ha JP, Tai YP, Tsang WW, Li MK. Double-blind, randomized trial comparing Harmonic Scalpel hemorrhoidectomy, bipolar scissors hemorrhoidectomy, and scissors excision: ligation technique. Dis Colon Rectum 2002;45(06):789-794

19 Sayfan J. Complications of Milligan-Morgan hemorrhoidectomy. Dig Surg 2001;18(02):131-133

20 Sielezneff I, Salle E, Lécuyer J, Brunet C, Sarles JC, Sastre B. [Early postoperative morbidity after hemorrhoidectomy using the Milligan-Morgan technic. A retrospective studies of 1,134 cases]. J Chir (Paris) 1997;134(5-6):243-247(Paris)

21 Pattana-arun J, Wesarachawit W, Tantiphlachiva K, Atithansakul P, Sahakitrungruang C, Rojanasakul A. A comparison of early postoperative results between urgent closed hemorrhoidectomy for prolapsed thrombosed hemorrhoids and elective closed hemorrhoidectomy. J Med Assoc Thai 2009;92(12): $1610-1615$

22 Longo A. Treatment of hemorrhoids disease by reduction of mucosa and haemorrhoidal prolapse with a circular suturing device: A new procedure. . Proceedings of the 6th World Congress of Endoscopic Surgery; 1998 June 3-6; Rome, Italy 
23 Burch J, Epstein D, Sari AB, et al. Stapled haemorrhoidopexy for the treatment of haemorrhoids: a systematic review. Colorectal Dis 2009;11(03):233-243, discussion 243

24 Chen JS, You JF. Current status of surgical treatment for hemorrhoids-systematic review and meta-analysis. Chang Gung Med J 2010;33(05):488-500

25 Guenin MO, Rosenthal R, Kern B, et al. Long-term results and patient satisfaction after Ferguson's haemorrhoidectomy. Dis Colon Rectum 2005;48:1523-1527

26 Ceci F, Picchio M, Palimento D, Calì B, Corelli S, Spaziani E. Long-term outcome of stapled hemorrhoidopexy for Grade III and Grade IV hemorrhoids. Dis Colon Rectum 2008;51(07):1107-1112

27 Festen S, van Geloven AAW, Gerhards MF. Redo procedure for prolapse and haemorrhoids (PPH) for persistent and recurrent prolapse after PPH. Dig Surg 2009;26(05):418-421
28 Kim JS, Vashist YK, Thieltges S, et al. Stapled hemorrhoidopexy versus Milligan-Morgan hemorrhoidectomy in circumferential third-degree hemorrhoids: long-term results of a randomized controlled trial. J Gastrointest Surg 2013;17(07):1292-1298

29 Naldini G, Martellucci J, Talento P, Caviglia A, Moraldi L, Rossi M. New approach to large haemorrhoidal prolapse: double stapled haemorrhoidopexy. Int J Colorectal Dis 2009;24(12):1383-1387

30 Stuto A, Favero A, Cerullo G, Braini A, Narisetty P, Tosolini G. Double stapled haemorrhoidopexy for haemorrhoidal prolapse: indications, feasibility and safety. Colorectal Dis 2012;14(07): e386-e389

31 Thaha MA, Campbell KL, Kazmi SA, et al. Prospective randomised multi-centre trial comparing the clinical efficacy, safety and patient acceptability of circular stapled anopexy with closed diathermy haemorrhoidectomy. Gut 2009;58(05):668-678 